\title{
Evaluation of in vitro glistening formation in hydrophobic acrylic intraocular lenses
}

This article was published in the following Dove Press journal:

Clinical Ophthalmology

24 July 2013

Number of times this article has been viewed

\section{Brett E Thomes \\ Thomas A Callaghan}

Alcon Research Ltd (A Novartis Company), Fort Worth, TX, USA

Correspondence: Brett E Thomes Alcon Research Ltd (A Novartis Company), 620I South Freeway, Fort Worth, TX, USA

$\mathrm{Tel}+\mathrm{I} 8175686429$

Fax +I 8176153596

Email brett.thomes@alconlabs.com
Purpose: To evaluate the impact of continuous manufacturing process improvements on glistening formation in AcrySof hydrophobic acrylic intraocular lenses (IOLs) by comparing lenses manufactured in 2003 with lenses manufactured in 2012.

Methods: Glistenings were experimentally created as aqueous-filled microvacuoles utilizing an accelerated laboratory method by immersing the lens in water at $45^{\circ} \mathrm{C}$ for 24 hours and then reducing the temperature to $37^{\circ} \mathrm{C}$ for 2.5 hours. To determine the impact of continuous improvements on glistening formation, AcrySof IOLs (Alcon Laboratories, Inc) Model SB30 AL manufactured in 2003 were compared with AcrySof IOLs Model SN60 WF manufactured in 2012.

Results: Glistenings were present in all lenses after the accelerated microvacuole test method. The mean microvacuole density for IOLs manufactured in 2003 was 315.7 microvacuoles per square millimeter $\left(\mathrm{MVs} / \mathrm{mm}^{2}\right)$ with a glistening severity less than $100 \mathrm{MVs} / \mathrm{mm}^{2}$ in $1.0 \%$ of the IOLs. The mean microvacuole density for IOLs manufactured in 2012 was $39.9 \mathrm{MVs} / \mathrm{mm}^{2}$ with a glistening severity less than $100 \mathrm{MVs} / \mathrm{mm}^{2}$ in $95.2 \%$ of the IOLs. Laboratory-induced microvacuole density was significantly lower in IOLs manufactured in 2012 (mean $39.9 \mathrm{MVs} / \mathrm{mm}^{2}$ ) relative to IOLs manufactured in 2003 (mean $315.7 \mathrm{MVs} / \mathrm{mm}^{2}$ ) as indicated by the Wilcoxon test of significance $(P<0.0005)$.

Conclusion: AcrySof IOLs recently manufactured in 2012 demonstrated a significant reduction in glistening density ( $87 \%$ reduction in mean density) as a result of continuous manufacturing process improvements compared with IOLs manufactured in 2003.

Keywords: microvacuoles, glistenings, AcrySof, intraocular lenses

\section{Introduction}

Glistenings are fluid-filled microvacuoles that form within the matrix of the intraocular lens (IOL) when exposed to an aqueous environment. The existence of glistenings was first reported in polymethylmethacrylate (PMMA) lenses in $1985 .^{1}$ The presence of these microvacuoles or glistenings in the lens material matrix has been noted in virtually all IOL materials, including PMMA, ${ }^{2}$ silicone, ${ }^{3}$ hydrophobic acrylic ${ }^{4}$ and hydrophilic acrylic. ${ }^{5}$ They have most often been reported in hydrophobic acrylic IOLs. ${ }^{5-9}$

Glistenings are typically observed within a few months of surgery and plateau approximately 1 year after surgical implantation of the IOL. Glistenings appear as small reflections of light during slit lamp examination under oblique illumination. ${ }^{4}$ Glistenings are found within the network of the IOL material and vary in size and density depending on the IOL material. Glistening formation is influenced by a variety of factors, such as IOL material, manufacturing processes, packaging, and temperature fluctuations. ${ }^{4,10,11}$ 
Peer-reviewed literature has reported large variability in the incidence and severity of glistenings. The glistenings phenomenon has been extensively studied in AcrySof IOLs. Tognetto et al evaluated glistenings in foldable IOLs of various materials. ${ }^{12}$ Glistenings were present in all IOL materials or groups. The IOL material/type had a significant effect on the grade of the glistenings. Only $40 \%$ of AcrySof IOLs had glistenings after 1 month but that number increased to $67.5 \%$ after 2 years. Most of the AcrySof IOLs had only trace glistenings with some moderate levels of glistenings but no IOLs had severe enough glistenings to impair visual function.

Colin et al evaluated 111 eyes in 74 patients with AcrySof Natural IOLs and observed that $86.5 \%$ of implanted IOLs had glistenings upon follow-up between 11 and 80 months. ${ }^{13}$ Using a glistening scale of 0 : none, 1 : moderate, 2 : dense, the follow-up was statistically significantly longer in eyes with grade $2(P=0.01)$. Only $73.8 \%$ of the IOLs had glistenings when follow-up was less than 2 years. On the other hand, $94.2 \%$ of the IOLs had glistenings when the follow-up was longer than 2 years. They also categorized $45.9 \%$ of lenses as grade 2 (dense). However, there was no significant difference in visual acuity (corrected distance visual acuity [CDVA]) between glistening severity groups. These results are consistent with most studies regarding glistening formation in AcrySof IOLs that found no impact on visual function.

This study is aimed at quantifying the reduction of glistening formation in the AcrySof IOLs after continuous manufacturing process improvements. It examines if the manufacturing process improvements over the last decade have significantly reduced the incidence and severity of glistenings in AcrySof IOLs as determined by an accelerated laboratory method.

With technological advancements, continuous improvements have been implemented in the manufacturing process for AcrySof IOLs. These improvements were implemented following extensive review of the manufacturing processes utilized in making AcrySof IOLs. As a result, numerous process improvements were implemented in the formulation, cast molding, and curing operations. These improvements include the implementation of advanced manufacturing equipment, improved environmental controls, and tightened process controls/specifications. Specific details of these improvements cannot be fully disclosed due to the proprietary nature of the IOL manufacturing process. The current study was designed to evaluate if these improvements have had an effect on the glistening formation in AcrySof IOLs by comparing lenses manufactured in 2003 to IOLs manufactured in 2012.

\section{Methods}

\section{Test materials}

AcrySof IOLs (Alcon Laboratories, Inc, Fort Worth, TX, USA), manufactured at different time periods, were used for microvacuole testing to determine the cumulative effects of these process improvements on the formation of glistenings. The microvacuole generation process and subsequent imaging were completed on AcrySof Natural IOLs Model SB30 AL ( $\mathrm{n}=100$, from two lots) manufactured in 2003 and AcrySof Natural IQ Model SN60 WF IOLs ( $n=270$, from nine lots) manufactured in 2012. This sample size allows a $95 \%$ confidence level $(\mathrm{CI} ; \alpha=0.05)$ with $90 \%$ power for microvacuole density measurements based on historical data (1-sample Z-test, MiniTab ${ }^{\circledR} 15$; Minitab, Inc, State College, PA, USA) with a standard deviation (SD) of 150 and an expected difference in 100 microvacuoles per square millimeter $\left(\mathrm{MV} / \mathrm{mm}^{2}\right)$. Multiple lots were tested for each group to capture any other potential variation. The test samples consisted of IOLs within 27.0-34.0 dioptric (D) power range.

The lenses manufactured in 2003 were stored in a dry state under controlled room temperature and humidity conditions (temperature: $22^{\circ} \mathrm{C} \pm 4^{\circ} \mathrm{C}$ and relative humidity: $50 \% \pm 20 \%$ ). Internal studies on the glistening response and storage conditions with AcrySof have shown that glistening formation will not be induced if samples are stored within these temperature and relative humidity ranges.

\section{Accelerated microvacuole test method}

Glistenings or microvacuoles were created by utilizing an accelerated laboratory method on AcrySof IOLs manufactured in 2003 and 2012. When observed in a laboratory, glistenings are referred as "microvacuoles". To generate microvacuoles, each lens was placed in a constant temperature water bath set at $45^{\circ} \mathrm{C} \pm 1^{\circ} \mathrm{C}$. After 24 hours, samples were moved to a $37^{\circ} \mathrm{C} \pm 1^{\circ} \mathrm{C}$ water bath where they remained for another 2.5 hours. At the end of that time, samples were analyzed.

The microvacuole analysis system consists of a microscope equipped with a heated stage, a CCD camera, a computer, and software. This allows for the visual observation and analysis of size and density of the microvacuoles at a specified temperature and location. For measurement, each lens was moved to a heated stage to maintain the temperature of the lens at $37^{\circ} \mathrm{C}$ during imaging. The constant temperature helps to maintain microvacuole size and density during imaging. The lens was then observed with the microscope, which includes a digital camera for imaging 
and a micrometer to achieve consistency in imaging at the same regions, from lens to lens. Using the camera, a series of images (approximately $1 \mathrm{~mm}^{2}$ ) were captured through the microscope at $100 \times$ magnification.

The size and density of the microvacuole were observed and imaged in three regions of the lens - the edge, mid, and center regions. The images for a $6.0 \mathrm{~mm}$ IOL are taken at $0.6 \mathrm{~mm}$ from the edge of the optic (edge), $1.6 \mathrm{~mm}$ from the edge of the optic (mid), and $2.6 \mathrm{~mm}$ from the edge of the optic (center).

For the lenses manufactured in 2012, a fourth image was also captured. The entire lens was scanned in order to identify a region of maximum density and to ensure the worst case location was captured for analysis. The focus was adjusted on each image to place the focal plane inside the IOL containing the highest density of microvacuoles. The resultant images were captured and analyzed using a proprietary image analysis program. The analysis consists of a series of filtering techniques to highlight the microvacuoles in the image. Once microvacuoles were highlighted by the software, the density and size of the microvacuoles (units: number of microvacuole per square millimeter $\left[\mathrm{MVs} / \mathrm{mm}^{2}\right]$ ) were recorded. Summary data for each measured region of each lens were tabulated. On each lens, the region with the highest microvacuole density was selected for statistical analysis.

A Levene's test was conducted to determine if the differences in variances between the two groups were significant. A Wilcoxon test of significance was performed (MiniTab $\left.{ }^{\circledR} 15\right)$ based on the null hypothesis that the estimated median for the IOLs manufactured in 2012 was equal to the estimated median for the IOLs manufactured in 2003.

\section{Results}

\section{Microvacuole density after accelerated microvacuole test method}

Glistenings were present in all lenses after the accelerated microvacuole test method. The mean microvacuole density for IOLs manufactured in 2003 was $315.7 \mathrm{MVs} / \mathrm{mm}^{2}$, $\mathrm{SD} \pm 149.4 \mathrm{MVs} / \mathrm{mm}^{2}$ (Table 1). One percent of IOLs had a glistening severity of less than $50 \mathrm{MVs} / \mathrm{mm}^{2}$ and $1.0 \%$ of IOLs had a glistening severity of less than 100 $\mathrm{MVs} / \mathrm{mm}^{2}$.

The mean microvacuole density for IOLs manufactured in 2012 was $39.9 \mathrm{MVs} / \mathrm{mm}^{2}, \mathrm{SD} \pm 35.0 \mathrm{MVs} / \mathrm{mm}^{2}$ (Table 1). In comparison to the IOLs manufactured in 2003, $79.3 \%$ of IOLs had a glistening severity of less than $50 \mathrm{MVs} / \mathrm{mm}^{2}$ and $95.2 \%$ of IOLs had a glistening severity of less than $100 \mathrm{MVs} / \mathrm{mm}^{2}$.
Table I

\begin{tabular}{llll}
\hline $\begin{array}{l}\text { IOL manufacturing } \\
\text { date }(\mathbf{n}=\text { sample } \\
\text { size })\end{array}$ & $\begin{array}{l}\text { Mean density } \\
\left(\mathbf{M V s} / \mathbf{m m}^{2}\right)\end{array}$ & $\begin{array}{l}\text { Standard } \\
\text { deviation } \\
\left(\mathbf{M V s} / \mathbf{m m}^{2}\right)\end{array}$ & $\begin{array}{l}\text { Density } \\
\text { range } \\
\left(\mathbf{M V s} / \mathbf{m m}^{2}\right)\end{array}$ \\
\hline $2003(\mathrm{n}=100)$ & 315.7 & 149.4 & $18.6-832.2$ \\
$2012(\mathrm{n}=270)$ & 39.9 & 35.0 & $6.8-265.9$ \\
\hline
\end{tabular}

Abbreviation: IOL, intraocular lens.

The median microvacuole densities for IOLs manufactured in 2012 and 2003 were $30.5 \mathrm{MVs} / \mathrm{mm}^{2}$ and $284.8 \mathrm{MVs} / \mathrm{mm}^{2}$, respectively (Table 2 ).

The Levene's test indicated that the difference in variances between the two groups was significant $(P<0.05)$. This result indicated that the IOLs manufactured in 2012 had lower variance than the IOLs manufactured in 2003. The Wilcoxon test of significance indicated that the median results from these two populations were significantly different $(P<0.0005)$. Thus, microvacuole density in IOLs manufactured in 2012 (median: 30.5, mean \pm SD: $39.9 \pm 35.0 \mathrm{MVs} / \mathrm{mm}^{2}$; Figures 1-3) was significantly lower than that in IOLs manufactured in 2003 (median: 284.8, mean $\pm \mathrm{SD}: 315.7 \pm 149.4 \mathrm{MVs} / \mathrm{mm}^{2}$ ).

\section{Discussion}

The mechanism of glistening formation has been related to temperature changes in the IOL and an increase in free volume within the matrix of the IOL material. ${ }^{14}$ Each IOL material has a specific, maximum equilibrium water content. At higher temperatures, the lens polymer may absorb water to its maximum capacity. ${ }^{15,16}$ If the temperature of the material is then decreased, the maximum equilibrium water content of the material may drop, producing conditions in which the maximum water content of the lens material is exceeded and the excess water will phase-separate from the polymer matrix. Under these conditions, glistenings have the potential to form, grow, and become visible. AcrySof IOLs are made of a hydrophobic material and, as such, are prone to phase separation when the temperature of the IOL is decreased under in situ conditions. When excess water is close to the surface of the lens, it can readily diffuse out of the matrix without causing glistenings. However, if it is sufficiently far from the surface of the lens, the excess water will collect in

Table 2

\begin{tabular}{llll}
\hline $\begin{array}{l}\text { IOL manufacturing } \\
\text { date }(\mathbf{n}=\text { sample } \\
\text { size) }\end{array}$ & $\begin{array}{l}\text { 50th percentile, } \\
\text { median } \\
\left(\mathbf{M V s} / \mathbf{m m}^{2}\right)\end{array}$ & $\begin{array}{l}\text { 75th } \\
\text { percentile } \\
\left(\mathbf{M V s} / \mathbf{m m}^{2}\right)\end{array}$ & $\begin{array}{l}\text { 95th } \\
\text { percentile } \\
\left(\mathbf{M V s} / \mathbf{m m}^{2}\right)\end{array}$ \\
\hline $2003(\mathrm{n}=100)$ & 284.8 & 394.9 & 617.0 \\
$2012(\mathrm{n}=270)$ & 30.5 & 44.1 & 98.3 \\
\hline
\end{tabular}

Abbreviation: IOL, intraocular lens. 


\section{A}

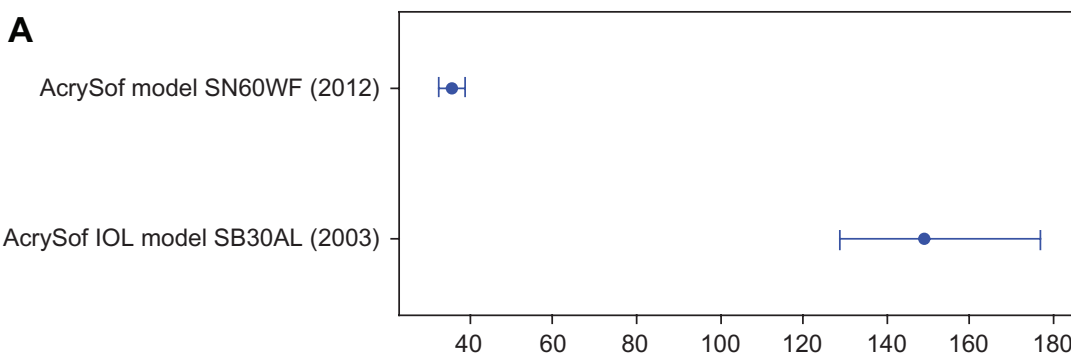

\begin{tabular}{|lr|}
\hline \multicolumn{2}{|c|}{ Levene's test } \\
Test statistic & 192.09 \\
$P$-value & 0.000 \\
\hline
\end{tabular}

$95 \%$ bonferroni confidence intervals for SD

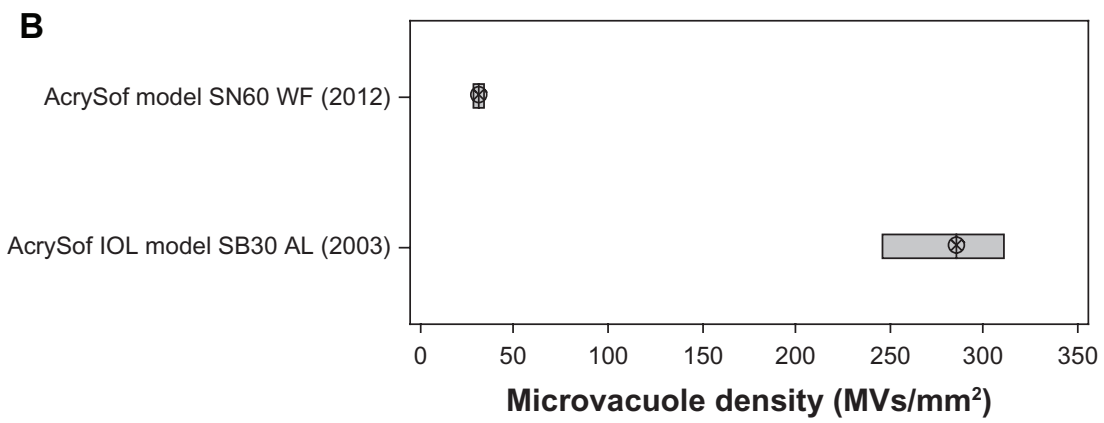

Figure I Comparison of mean microvacuole density and variances for AcrySof intraocular lenses manufactured in 2003 and 2012 after process continuous improvements. Note: (A) Comparison of variances; (B) Comparison of medians. 95\% confidence interval for (B).

Abbreviations: SD, standard deviation; IOL, intraocular lens.

discrete pockets inside the IOL, forming microvacuoles or glistenings. High diopter IOLs in the 27.0-34.0 diopter range were used to simulate worst case diffusion limits and is supported by the Moreno-Montanes et al study which indicates a dependence of diopter on glistenings in the clinic. ${ }^{17}$ As tem- perature conditions change, water may be re-absorbed into the polymer in areas where these glistenings were formed. ${ }^{6}$ When this glistening formation process is repeated in the laboratory in the same IOL, the glistenings will reappear in the same location within the matrix of the material. ${ }^{9}$

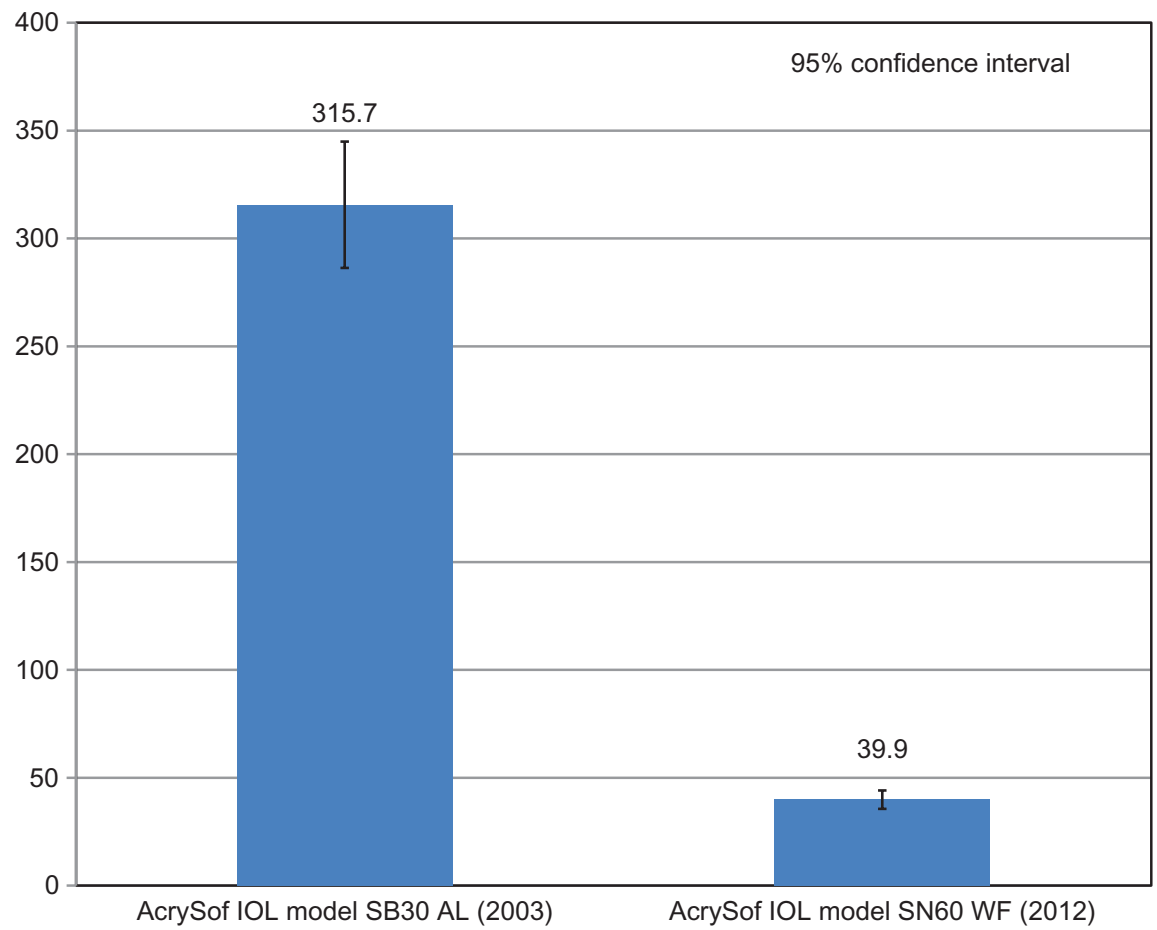

Figure 2 Mean microvacuole density for AcrySof intraocular lenses manufactured in 2003 and 2012 after years of continuous process improvements. Abbreviation: IOL, intraocular lens. 


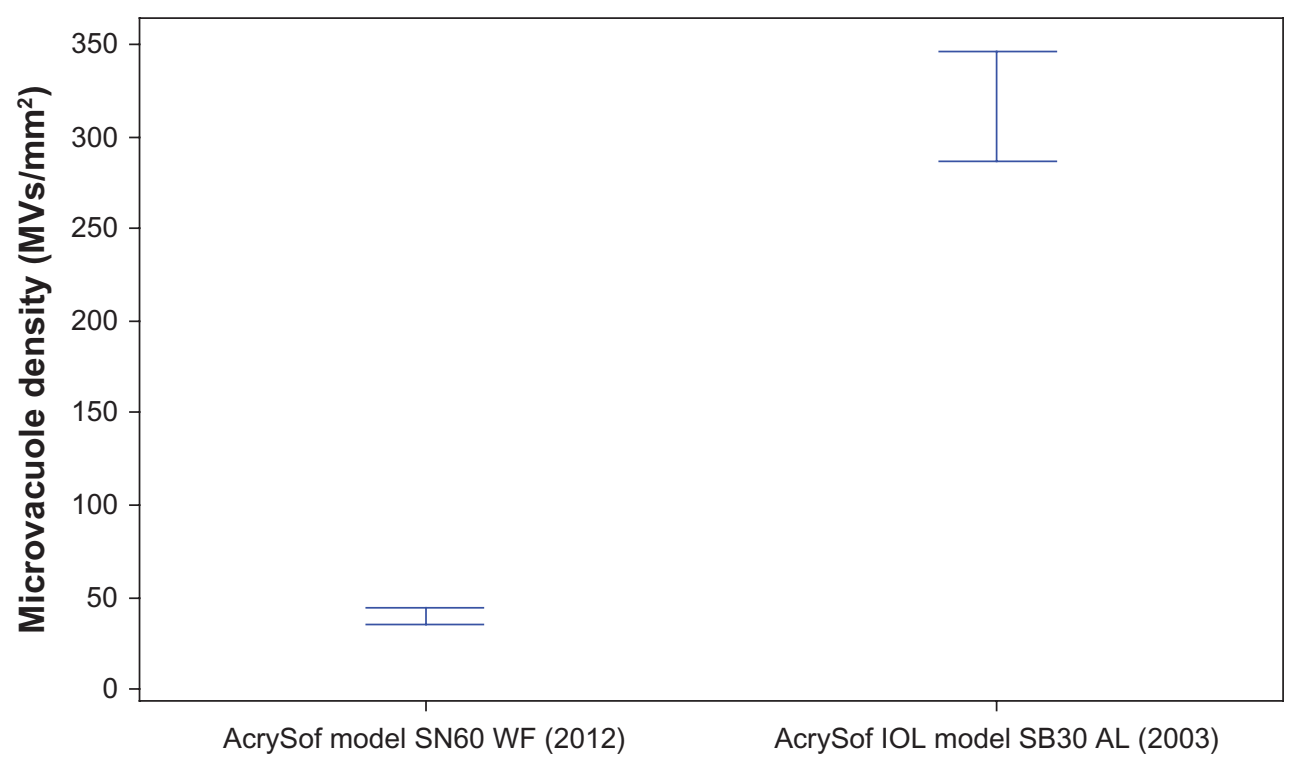

Figure 3 Comparison of mean microvacuole density for AcrySof intraocular lenses manufactured in 2003 and 2012 after years of continuous process improvements. $(P<0.0005)$. Abbreviation: IOL, intraocular lens.

A systematic, repeatable method of inducing and measuring the size and density of microvacuoles in vitro is necessary to assess and approximate the in-eye appearance of microvacuoles. Such a method can provide a valuable in vitro model of in vivo performance. Numerous in vitro studies have been conducted and evaluated microvacuole performance. ${ }^{15,16,18,19}$ It is not certain that the glistenings produced with these various methods arise due to the same mechanism or are of the same kind as those observed in patients. However, in vitro experimentation has demonstrated that changes in temperature can be used to artificially induce glistening or microvacuole formation in lens materials. ${ }^{15,16}$ The rate of these temperature fluctuations has a significant effect on the extent of glistening formation. It has also been noted by Oshika et $\mathrm{al},{ }^{18}$ that glistening formation induced in vitro produces extreme cases that appear exaggerated compared with clinical observations. Although in vitro analysis may provide an assessment of the tendency of a material to form glistenings, the correlation between in vitro test results and in vivo observations has not been established. ${ }^{19}$ This study does not simulate temperature fluctuations in the human eye; however, a decrease of $8^{\circ} \mathrm{C}$ creates extreme conditions to determine the IOL's propensity to form microvacuoles.

This in vitro analysis of experimentally induced microvacuoles was designed to evaluate the impact of continuous manufacturing process improvements in AcrySof IOL materials on glistening formation in AcrySof IOLs. These results demonstrate that glistening or microvacuole formation is significantly reduced in the most recent AcrySof IOLs. The mean density of microvacuoles seen in the AcrySof lenses manufactured in 2012 (mean: $39.9 \mathrm{MVs} / \mathrm{mm}^{2}$ ) was significantly lower than that of IOLs manufactured in 2003 (mean: $315.7 \mathrm{MVs} / \mathrm{mm}^{2} ; P<0.0005$ ) (Figure 3).

Perhaps the most important issue surrounding glistenings is their effect on vision. Multiple studies have reported that the presence of glistenings does not affect vision. ${ }^{13,18,20,22}$ Oshika et $\mathrm{al}^{18}$ studied the optical effect of microvacuoles induced by temperature changes in vitro on the AcrySof IOL Model MA60BM. The study reported no significant effect on spectral transmittance, scattering, modulation transfer function, or resolving power at various contrasts for similar microvacuole density levels measured in our study. Hayashi et $\mathrm{al}^{20}$ investigated the long-term effect of glistenings of various IOLs on visual function and optical aberrations after cataract surgery, as measured by the mean uncorrected visual acuity (VA), photopic and mesopic contrast VA and glare VA, and higher-order aberrations. In more than 10 years after implantation, the visual function and optical aberrations were not significantly different for eyes that received a hydrophobic acrylic IOL compared with eyes that received silicone or PMMA IOLs, although glistenings were significantly more remarkable with the acrylic IOL $(P<0.0001)$. Optical measurements indicated that there was no significant difference in VA, glare, and contrast sensitivity. In up to 3 years of follow-up of 136 patients, Minami et a ${ }^{21}$ observed no relationship between severity of glistening and clinical VA or contrast sensitivity. Colin et al ${ }^{13}$ reported similar clinical results and demonstrated no statistically significant difference in VA, glare disability, and contrast sensitivity between groups with or without glistenings. 


\section{Conclusion}

Many factors may contribute to differences in glistening formation within IOLs, including IOL materials and manufacturing processes. These results demonstrate that the level of glistenings in recently manufactured AcrySof IOLs is significantly reduced as a result of continuous improvements since 2003 in the manufacturing process.

\section{Acknowledgments}

Manoj Venkiteshwar, Steve Van Noy, Val Injev, and Mutlu Karakelle from Alcon Research, Ltd provided technical help and writing assistance. Renea Stasaski and Bryan Wiens from Alcon Research, Ltd performed data analysis. Christina Valentine-Leary and Marsha Hall of KnowledgePoint360 Group (Lyndhurst, NJ, USA and Newtown, PA, USA) provided editorial assistance on the final manuscript draft, with support from Alcon Laboratories (Fort Worth, TX, USA).

\section{Disclosure}

The study was funded by and conducted at Alcon Research, Ltd, Fort Worth, TX, USA. Both authors are employees of Alcon Research, Ltd.

\section{References}

1. Ballin N. Glistenings in injection-molded lens. J Am Intraocul Implant Soc. 1984;10(4):473.

2. Wilkins E, Olson RJ. Glistenings with long-term follow-up of the Surgidev B20/20 polymethylmethacrylate intraocular lens. Am $J$ Ophthalmol. 2001;132(5):783-785.

3. Cisneros-Lanuza A, Hurtado-Sarrió M, Duch-SamperA, Gallego-Pinazo R, Menezo-Rozalén JL. Glistenings in the Artiflex phakic intraocular lens. J Cataract Refract Surg. 2007;33(8):1405-1408.

4. Miyata A, Uchida N, Nakajima K, Yaguchi S. Clinical and experimental observation of glistening in acrylic intraocular lenses. Jpn J Ophthalmol. 2001;45(6):564-569.

5. Rønbeck M, Behndig A, Taube M, Koivula A, Kugelberg M. Comparison of glistenings in intraocular lenses with three different materials: 12-year follow-up. Acta Ophthalmol. 2013;91(1):66-70.
6. Miyata A, Yaguchi S. Equilibrium water content and glistenings in acrylic intraocular lenses. J Cataract Refract Surg. 2004;30(8):1768-1772.

7. Mönestam E, Behndig A. Impact on visual function from light scattering and glistenings in intraocular lenses, a long-term study. Acta Ophthalmol. 2011;89(8):724-728.

8. Dhaliwal DK, Mamalis N, Olson RJ, et al. Visual significance of glistenings seen in the AcrySof intraocular lens. $J$ Cataract Refract Surg. 1996;22(4):452-457.

9. Werner L. Glistenings and surface light scattering in intraocular lenses. $J$ Cataract Refract Surg. 2010;36(8):1398-1420.

10. Dick HB, Olson RJ, Augustin AJ, Schwenn O, Magdowski G, Pfeiffer N. Vacuoles in the Acrysof intraocular lens as factor of the presence of serum in aqueous humor. Ophthalmic Res. 2001;33(2):61-67.

11. Nishihara H, Kageyama T, Ohnishi T, et al. Glistenings in lathe-cut acrylic intraocular lens. Ganka Shujutsu. 2000;13:227-230.

12. Tognetto D, Toto L, Sanguinetti G, Ravalico G. Glistenings in foldable intraocular lenses. J Cataract Refract Surg. 2002;28(7):1211-1216.

13. Colin J, Praud D, Touboul D, Schweitzer C. Incidence of glistening with the latest generation of yellow-tinted hydrophobic intraocular lenses. $J$ Cataract Refract Surg. 2012;38(7):1140-1146.

14. Waite A, Faulkner N, Olson RJ. Glistenings in the single-piece, hydrophobic, acrylic intraocular lenses. Am J Ophthalmol. 2007;144(1): 143-144.

15. Gregori NZ, Spencer TS, Mamalis N, Olson RJ. In vitro comparison of glistening formation among hydrophobic acrylic intraocular lenses. J Cataract Refract Surg. 2002;28(7):1262-1268.

16. Omar O, Pirayesh A, Mamalis N, Olson RJ. In vitro analysis of AcrySof intraocular lens glistenings in AcryPak and Wagon Wheel packaging. J Cataract Refract Surg. 1998;24(1):107-113.

17. Moreno-Montanes J, Alvarez A, Rodriguez-Conde R, FernandezHortelano A. Clinical factors related to the frequency and intensity of glistening in AcrySof intraocular lenses. J Cataract Refract Surg. 2003;29(10):1980-1984.

18. Oshika T, Shiokawa Y, Amano S, Mitomo K. Influence of glistenings on the optical quality of acrylic foldable intraocular lens. Br JOphthalmol. 2001;85(9):1034-1037.

19. Colin J, Orignac I. Glistenings on intraocular lenses in healthy eyes: effects and associations. J Refract Surg. 2011;27(12):869-875.

20. Hayashi K, Hirata A, Yoshida M, Yoshimura K, Hayashi H. Long-term effect of surface light scattering and glistenings of intraocular lenses on visual function. Am J Ophthalmol. 2012;154(2):240-251.

21. Minami H, Toru K, Hiroi K, Kazama S. Glistenings of acrylic intraocular lenses. Jpn J Clin Ophthalmol. 1999;53(5):991-994.
Clinical Ophthalmology

\section{Publish your work in this journal}

Clinical Ophthalmology is an international, peer-reviewed journal covering all subspecialties within ophthalmology. Key topics include: Optometry; Visual science; Pharmacology and drug therapy in eye diseases; Basic Sciences; Primary and Secondary eye care; Patient Safety and Quality of Care Improvements. This journal is indexed on Submit your manuscript here: http://www.dovepress.com/clinical-ophthalmology-journal

\section{Dovepress}

PubMed Central and CAS, and is the official journal of The Society of Clinical Ophthalmology (SCO). The manuscript management system is completely online and includes a very quick and fair peer-review system, which is all easy to use. Visit http://www.dovepress.com/ testimonials.php to read real quotes from published authors. 